\title{
The ankle ligament reconstruction-return to sport after injury (ALR-RSI) is a valid and reproducible scale to quantify psychological readiness before returning to sport after ankle ligament reconstruction
}

\author{
François Sigonney ${ }^{1} \cdot$ Ronny Lopes $^{2}$ • Pierre-Alban Bouché ${ }^{1} \cdot$ Elliott Kierszbaum $^{1} \cdot$ Aymane Moslemi $^{1}$. \\ Philippe Anract ${ }^{1} \cdot$ Alexandra Stein $^{1} \cdot$ Alexandre Hardy $^{3}$
}

Received: 11 January 2020 / Accepted: 21 April 2020 / Published online: 30 April 2020

(c) The Author(s) 2020

\begin{abstract}
Purpose Chronic ankle instability is the main complication of ankle sprains and requires surgery if non-operative treatment fails. The goal of this study was to validate a tool to quantify psychological readiness to return to sport after ankle ligament reconstruction.

Methods The form was designed like the anterior cruciate ligament-return to sport after injury scale and "Knee" was replaced by the term "ankle". The ankle ligament reconstruction-return to sport after injury (ALR-RSI) scale was filled by patients who underwent ankle ligament reconstruction and were active in sports. The scale was then validated according to the international COSMIN methodology. The AOFAS and Karlsson scores were used as reference questionnaires.

Results Fifty-seven patients (59 ankles) were included, 27 women. The ALR-RSI scale was strongly correlated with the Karlsson score $(r=0.79$ [0.66-0.87]) and the AOFAS score $(r=0.8$ [0.66-0.87]). A highly significant difference was found in the ALR-RSI between the subgroup of 50 patients who returned to playing sport and the seven who did not: 68.8 (56.5-86.5) vs 45.0 (31.3-55.8), respectively, $p=0.02$. The internal consistency of the scale was high $(\alpha=0.96)$. Reproducibility of the test-retest was excellent ( $\rho=0.92 ; 95 \%$ CI $[0.86-0.96])$.

Conclusion The ALR-RSI is a valid, reproducible scale that identifies patients who are ready to return to the same sport after ankle ligament reconstruction. This scale may help to identify athletes who will find sport resumption difficult.

Level of evidence III.
\end{abstract}

Keywords ALR-RSI $\cdot$ Ankle $\cdot$ Ligament reconstruction $\cdot$ Psychological

\section{Introduction}

Ankle sprains are extremely frequent; they represent 15-20\% of all sport-related injuries. The frequency of diagnosed ankle sprains is 6000 cases per day in France and 24,000

François Sigonney

francois.sigonney@gmail.com

1 Orthopaedic Department, Cochin University Hospital, APHP Paris, Paris Descartes University, 27 rue du Faubourg Saint-Jacques, 75014 Paris, France

2 Orthopaedic Department, Pied Cheville Nantes Atlantique (Santé Atlantique Et Clinique Bretéché), Nantes, France

3 Clinique du Sport, 36 boulevard Saint-Marcel, 75005 Paris, France cases per day in the United States: they represent $4-7 \%$ of emergency department consultation [14]. Functional treatment (Rest, Ice, Compression, and Elevation) is the standard reference for acute ankle sprains. In most cases, it is sufficient for a complete recovery. However, $20 \%$ of patients develop chronic lateral ankle instability (CLAI) $[8,16]$, some require surgical treatment, particularly those who are young and athletic.

Anatomic repairs by retentioning and directly suturing the anterior talofibular ligament (ATFL) are accepted to be the gold standard for treatment of CLAI $[6,10]$ although arthroscopic anatomical ligament reconstruction is becoming more and more popular. Techniques are developed to perform anatomical reconstruction of the anterior talofibular ligament (ATFL) and the calcaneofibular ligament (CFL) 
with a tendon graft (gracilis) using an all-arthroscopic approach $[10-12,19]$. Ankle arthroscopy is increasingly used to treat CLAI, and offers an opportunity to assess and treat any associated injuries $[10,18,30]$ with reduced iatrogenesis [20, 21].

After sustaining ankle injury, the most important issues for athletes are to recover as fast as possible and to return to sport at their initial performance level. It has been noted that many patients after surgery do not return to sport activities at the same level as prior to the injury, even though they have recuperated good functional results [22, 25, 29].

Indeed, studies have shown that athletes go through different stages after an injury, so they must be not only physically, but also psychologically ready to return to the same sport at the same level [7, 26].

Scales to analyze the psychological readiness to return to sport after reconstructive surgery have been developed for other athletic injuries. Webster et al. [31] developed the anterior cruciate ligament-return to sport after injury (ACLRSI) a scale of 12 items, to quantify the psychological readiness of athletes to return to sport following surgical ACL reconstruction.

The scale measures athlete's emotions, confidence in performance, and appraisal in relation to return to sport. Gerometta et al. [9] adapted the score, to the return to sport after shoulder instability (treated by surgery or conservative management), with the shoulder instability-return to sport after injury (SIRSI) scale.

The main purpose of this study was to propose and to validate a similar tool to quantify psychological readiness to return to sport after ankle ligament reconstruction.

\section{Material and method}

This study was approved by an Institutional Review Board (CPP IDF III, Hôpital Tarnier-Cochin) (Ref. CPP: 3730NI; Ref CNRIPH: 19.06.17.35910). Informed consent was obtained from each patient.

\section{Study participants}

This study included patients who were active in sports and underwent ankle ligament reconstruction between January 2016 and May 2017. Patients were excluded if they did not practice sport.

An arthroscopic anatomical reconstruction of the lateral ankle ligaments $[11,12,19,23]$ was performed in all patients.

Fifty-seven patients were included (59 ankles), 27 $(47.4 \%)$ women and 30 men (Table 1) with a median of $3.0(2.5 ; 3.7)$ years after ankle ligament reconstruction.
Table 1 Participants

\begin{tabular}{|c|c|c|c|}
\hline Parameters & Values & $N$ & Statistics \\
\hline \multirow[t]{2}{*}{ Sex } & Women & 27 & $47.4 \%$ \\
\hline & Men & 30 & $52.6 \%$ \\
\hline Follow-up (years) & & 59 & $3.0(2.5 ; 3.7)$ \\
\hline ALR-RSI total & & 59 & $64.4(10.0 ; 100.0)$ \\
\hline Karlsson total & & 59 & $85.2(25.0 ; 100.0)$ \\
\hline AOFAS total & & 59 & $81.7(29.0 ; 00.0)$ \\
\hline \multirow[t]{2}{*}{ Sport recovery } & No & 7 & $12.1 \%$ \\
\hline & Yes & 52 & $88.1 \%$ \\
\hline \multirow[t]{3}{*}{ If yes } & Sport change & 14 & $27.0 \%$ \\
\hline & Same sport, inferior level & 12 & $23.0 \%$ \\
\hline & Same sport, same level & 26 & $50.0 \%$ \\
\hline \multirow[t]{3}{*}{ Sport level } & Competition & 29 & $49.2 \%$ \\
\hline & Casual leisure level & 4 & $6.8 \%$ \\
\hline & Regular leisure level & 26 & $44.0 \%$ \\
\hline \multirow[t]{17}{*}{ Sport } & Athletics & 1 & $1.7 \%$ \\
\hline & Badminton & 1 & $1.7 \%$ \\
\hline & Basketball & 7 & $11.9 \%$ \\
\hline & Running & 7 & $11.9 \%$ \\
\hline & Dance & 3 & $5.1 \%$ \\
\hline & Horse riding & 1 & $1.7 \%$ \\
\hline & Fitness & 1 & $1.7 \%$ \\
\hline & Soccer & 11 & $18.6 \%$ \\
\hline & Gymnastic & 2 & $3.4 \%$ \\
\hline & Handball & 5 & $8.5 \%$ \\
\hline & Multiple & 11 & $18.6 \%$ \\
\hline & Rugby & 2 & $3.4 \%$ \\
\hline & Archery & 1 & $1.7 \%$ \\
\hline & Triathlon & 1 & $1.7 \%$ \\
\hline & Volleyball & 1 & $1.7 \%$ \\
\hline & Walk & 3 & $5.1 \%$ \\
\hline & Table tennis & 1 & $1.7 \%$ \\
\hline
\end{tabular}

All patients were athletes who practiced: in competition: 29 ankles (49.2\%), as a regular leisure activity: 26 ankles (44.0\%) or an occasional leisure activity: four ankles (6.8\%). Arthroscopic anatomic reconstruction with tendon grafting was performed in all patients (Table 1).

\section{Ankle ligament reconstruction-return to sport after injury (ALR-RSI) scale}

The ALR-RSI scale is adapted from the ACL-RSI scale. The French version of the ACL-RSI scale has been shown to be valid [5], following international guidelines for the crosscultural adaptation of self-administered questionnaires [4].

The term "knee" has been replaced by the word "ankle" in the questionnaire (question 2, 4, 5, 6, 7, 8, and 9). For 
example, the question 2: "Do you think you are likely to re-injure your knee by participating in your sport?" was replaced by "Do you think you are likely to re-injure your ankle by participating in your sport?" (Fig. 1).
Validity and reproducibility of ALR-RSI

The final version was validated according to COSMIN international guidelines (COnsensus-based Standards for the selection of health status Measurement Instruments) [24]

Fig. 1 ALR-RSI scale

ALR-RSI scale

Please answer the following questions referring to your main sport prior to injury. For each question, tick a box $\square \checkmark$ between the two descriptions to indicate how you feel right now relative to the two extremes.

1.Are you confident that you can perform at your previous level of sport participation? Not at all confident $\quad \square \quad \square \quad \square \quad \square \quad \square \quad \square \quad \square \quad \square \quad \square \quad \square \quad \square \quad$ Fully confident $\begin{array}{lllllllllll}0 & 1 & 2 & 3 & 4 & 5 & 6 & 7 & 8 & 9 & 10\end{array}$

2.Do you think you are likely to re-injure your ankle by participating in your sport?

Extremely likely $\quad \square \quad \square \quad \square \quad \square \quad \square \quad \square \quad \square \quad \square \quad \square \quad \square \quad \square \quad$ Not likely at all $\begin{array}{lllllllllll}0 & 1 & 2 & 3 & 4 & 5 & 6 & 7 & 8 & 9 & 10\end{array}$

3.Are you nervous about playing your sport?

$\begin{array}{llllllllllllll}\text { Extremely nervous } & \square & \square & \square & \square & \square & \square & \square & \square & \square & \square & \square & \text { Not nervous at all }\end{array}$

4.Are you confident that your ankle will not give way by playing your sport?

Not at all confident $\square \quad \square \quad \square \quad \square \quad \square \quad \square \quad \square \quad \square \quad \square \quad \square \quad \square \quad$ Fully confident

$\begin{array}{lllllllllll}0 & 1 & 2 & 3 & 4 & 5 & 6 & 7 & 8 & 9 & 10\end{array}$

5.Are you confident that you could play your sport without concern for your ankle? Not at all confident $\quad \square \quad \square \quad \square \quad \square \quad \square \quad \square \quad \square \quad \square \quad \square \quad \square \quad \square \quad$ Fully confident $\begin{array}{lllllllllll}0 & 1 & 2 & 3 & 4 & 5 & 6 & 7 & 8 & 9 & 10\end{array}$

6.Do you find it frustrating to have to consider your ankle with respect to your sport?

$\begin{array}{llllllllllllll}\text { Extremely } & \square & \square & \square & \square & \square & \square & \square & \square & \square & \square & \square & \text { Not at all frustrating } \\ \text { frustrating } & 0 & 1 & 2 & 3 & 4 & 5 & 6 & 7 & 8 & 9 & 10\end{array}$


Fig. 1 (continued)

7.Are you fearful of re-injuring your ankle by playing your sport?

$\begin{array}{lllllllllllll}\text { Extremely fearful } & \square & \square & \square & \square & \square & \square & \square & \square & \square & \square & \square\end{array} \quad$ No fear at all

8.Are you confident about your ankle holding up under pressure?

$\begin{array}{lllllllllllllll}\text { Not at all confident } & \square & \square & \square & \square & \square & \square & \square & \square & \square & \square & \square & \text { Fully confident } \\ & 0 & 1 & 2 & 3 & 4 & 5 & 6 & 7 & 8 & 9 & 10 & \end{array}$

9.Are you afraid of accidentally injuring your ankle by playing your sport?

Extremely afraid $\quad \square \quad \square \quad \square \quad \square \quad \square \quad \square \quad \square \quad \square \quad \square \quad \square \quad \square \quad$ Not at all afraid

$\begin{array}{lllllllllll}0 & 1 & 2 & 3 & 4 & 5 & 6 & 7 & 8 & 9 & 10\end{array}$

10. Do thoughts of having to go through surgery and rehabilitation prevent you from playing your sport?

$\begin{array}{llllllllllllll}\text { All of the time } & \square & \square & \square & \square & \square & \square & \square & \square & \square & \square & \square\end{array}$ None of the time

\section{Are you confident about your ability to perform well at your sport?}

$\begin{array}{llllllllllllll}\text { Not at all confident } & \square & \square & \square & \square & \square & \square & \square & \square & \square & \square & \square & \text { Fully confident } \\ & 0 & 1 & 2 & 3 & 4 & 5 & 6 & 7 & 8 & 9 & 10\end{array}$

12. Do you feel relaxed about playing your sport?

$\begin{array}{rllllllllllllllll}\text { Not at all relaxed } & \square & \square & \square & \square & \square & \square & \square & \square & \square & \square & \square & & \text { Fully relaxed } \\ 0 & 1 & 2 & 3 & 4 & 5 & 6 & 7 & 8 & 9 & 10 & \end{array}$

ALR-RSI score total $x 100 / 120=\ldots \%$

The reference scales used were the American Orthopedic Foot \& Ankle Society (AOFAS) score [15] and the Karlsson score [27].

Patients were contacted, after giving their consent, they answered a self-administered questionnaire, which included the ALR-RSI scale, the AOFAS score, the Karlsson score and questions regarding their return to sport. The ALR-RSI was completed twice at a 15-day interval.

\section{The ALR-RSI}

The ALR-RSI scale, like the original version of the ACLRSI, was based on three components that have shown significant association with the return to sport: emotions, confidence in one's performance and evaluation of risk [26]. The ALR-RSI includes 12 questions with an 11-point Likert scale in the form of blocks to be ticked from 0 to 10 . The total score 
was calculated by adding up the values of the 12 answers then dividing the result by 1.2 to obtain a percentage. High scores corresponded to a positive psychological response.

\section{Statistical analysis}

The R software (version 3.5.0 spotted at the URL https:// www.R-project.org) was used to perform the statistical analyses. A sample size of 55 produces a two-sided $95 \%$ confidence interval with a width smaller than 0.28 when the estimate of Spearman's rank correlation is above 0.750 . Continuous quantitative variables were described by their mean, minimum and maximum. To describe the dichotomous variables, the number of events and their percentage were used. The Karlsson score and the AOFAS score were between 0 (very poor) and 100 (excellent). Construct validity was tested between the ALR-RSI, the total Karlsson score and its different subitems, and the AOFAS score by the Spearman coefficient. The Spearman correlation coefficient $\mathrm{r}$ was considered to be "strong" $(r>0.5)$, «moderate» $(0.5<r<0.3)$ or "strong" $(0.3<r<0.1)$. Discriminant validity was tested between the group of patients "that had returned to do sport" and the group "that had not returned to do sport" by the Mann and Whitney test. The internal consistency was evaluated by the correlation between the 12 items of the ALR-RSI, by the Cronbach alpha coefficient. Correlation among the items of the questionnaire was considered to be "excellent" if $\alpha \geq 0.90$. Reliability was evaluated on the $\rho$ intraclass correlation coefficient (ICCC). Reproducibility was considered to be "excellent" $(\rho>0.75)$, "good" $(0.75<\rho<0.40)$ or "weak" $(\rho<0.40)$. Feasibility was estimated by the percentage of missing responses and the ceiling and floor effects, corresponding to a percentage of patients who attained the minimum score (0) or the maximum score (10) for each question. $p<0.05$ was considered to be significant. The threshold of significance retained was $5 \%$ for a power of $80 \%$ and an alpha risk of $5 \%$.

\section{Results}

\section{Return to sport}

Fifty (87.7\%) patients returned to sport: 24 patients $(42.1 \%)$ returned to the same sport as before the injury at the same level, 13 patients (22.8\%) at an inferior level, and $13(22.8 \%)$ changed sport.

\section{Construct validity}

The ALR-RSI was strongly $(r>0.50)$ and significantly correlated to the Karlsson score: $r=0.79$ [0.66-0.87] and the AOFAS score: $r=0.8$ [0.66-0.87] (Tables 2 and 3).

\section{Discriminant validity}

A highly significant difference was found in the ALR-RSI between the subgroup of 50 patients who returned to playing sport and the seven who did not: $68.8(56.5-86.5)$ vs 45.0 (31.3-55.8), respectively, $p=0.02$

\section{Feasibility}

None of the answers were missing.

The floor effect, corresponding to the patients with the lowest score for each question, varied, between 0 and $1.7 \%$, and the ceiling effect, corresponding to the percentage with the highest score for each question varied between 6.7 and $33.8 \%$.

\section{Reliability}

Reliability was evaluated on the $\rho$ intraclass correlation coefficient (ICCC). The reproducibility was "excellent" with a $\rho$ intraclass correlation coefficient of 0.92 [0.86-0.96]. The median ALR-RSI score was 66.3 (45.6-85.8) when it was filled for the first time and $57.1(38.1-79.0)$ the second time (Fig. 2, Table 4).

\section{Internal consistency}

The internal consistency of the scale measuring the strength of the correlation between the 12 items was "excellent" with a Cronbach alpha coefficient of 0.96 .

Table 3 Correlation the ALR-RSI score and the AOFAS score

\begin{tabular}{lll}
\hline Coefficient & ALR-RSI $(/ 100)$ & AOFAS tot $(/ 100)$ \\
\hline Spearman & $66.7(47.5-85.8)$ & $88.0(74.0-94.0)$ \\
& & $0.8[0.66-0.87]$ \\
\hline
\end{tabular}

Table 2 Correlation the ALR-RSI score and the Karlsson score

\begin{tabular}{llllllll}
\hline Coefficient & ALR-RSI (/100) & Karlsson tot (/100) & Pain (/36) & $\begin{array}{l}\text { Other symptoms } \\
(/ 28)\end{array}$ & ADL (/68) & Sport (/20) & ARQL (/16) \\
\hline \multirow{3}{*}{ Spearman } & $66.7(47.5-85.8)$ & $91.1(80.1-96.7)$ & $32.0(28.0-35.0)$ & $25.0(20.0-27.0)$ & $67.0(63.5-68.0)$ & $17.0(13.5-20.0)$ & $12.0(9.0-14.5)$ \\
& & $0.79[0.66-0.87]$ & $0.70[0.50-0.81]$ & $0.60[0.42-0.74]$ & $0.65[0.45-0.78]$ & $0.82[0.69-0.90]$ & $0.79[0.66-0.87]$ \\
\hline
\end{tabular}




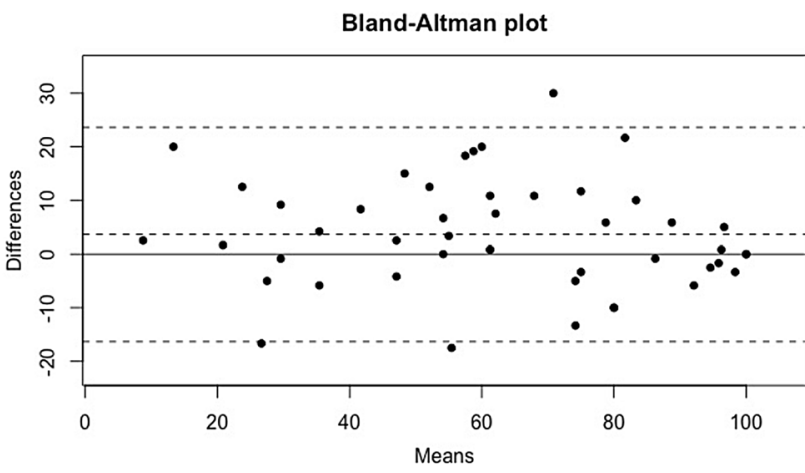

Fig. 2 Reproducibility of the ALR-RSI score with the test-retest: Bland-Altman plot

\section{Discussion}

The principal findings of the study were that the ALR-RSI represented a valid and reliable instrument, that can identify patients who are psychologically ready to return to the same sport, after ankle ligament reconstruction.

Patients selected for the surgery are usually young and athletic, and the most important goal of ankle ligament reconstruction is to enable them to return to their prior level in sports [14, 25, 29]. After well-conducted surgery and physical therapy, some patients experience failure or a decrease in their performance, without physically objectifiable reasons. Indeed, patients have to be ready not only physically, but also psychologically, to resume sports after a surgical intervention.

At a median $3.0(2.5 ; 3.7)$ years' follow-up, return to sport was possible for $87.7 \%$ of patients in this study. Those results are similar to what is reported in the literature. In a prospective study [18], the rate of return to the same level of sports following arthroscopic treatment of CLAI was $90 \%$ in the repair group and $80 \%$ in the reconstruction group, for recreational athletes and $73 \%$ after repair compared to $48 \%$ after reconstruction, for competitive athletes. Maffulli et al. [22] published the long-term results ( 9 years) on athletes, following a Bröstrom procedure, $58 \%$ were able to return to their preinjury level, $16 \%$ at a lower level, and $26 \%$ abandoned active sport participation. Nery et al. [25] published also the long-term results (9.8 years) following arthroscopic Bröstrom Gould procedure, $26(86.7 \%)$ of the 30 active patients practiced sport at the same preoperative level, 3 $(10 \%)$ had changed to a lower level (the AOFAS score at the last follow-up for these three patients was 86, 97 and 44), and 1 (3.3\%) had given up sport (AOFAS score at the last follow-up: 87). Therefore, three of four patients, whose sports level decreased, had an excellent AOFAS score.
Table 4 Reproducibility of the ALR-RSI score with the test-retest

\begin{tabular}{lll}
\hline Coefficient & ALR-RSI 1 (/100) & ALR-RSI 2 (/100) \\
\hline & $66.3(45.6-85.8)$ & $57.1(38.1-79.0)$ \\
ICC & & $\rho=0.92[0.86-0.96]$ \\
\hline
\end{tabular}

The different functional scores concerning the ankle, the Karlsson score and the AOFAS score were chosen because they are the most commonly used.

However, their clinical value is not sufficient, for giving patients the permission to return to sport. They do not always correspond to the actual recovery of their athletic performance, because they inform on an objective state of ankle function without taking into consideration the psychological state. Their actual sport capacities were analyzed to circumvent that issue. The patients were specifically asked if they have returned at the same level as prior to the injury, at a lower level or abandoned a specific sport activity. This allows better insight into their real recovery.

A systematic review published by Ardern et al. [2], looked into the psychological factors associated with returning to sport following injury. They showed that motivation, confidence and low fear were associated with an increased likelihood of returning to the preinjury level. On the other hand, fear stood out as the strongest negative emotion preventing a rapid and full return to sport. It has been shown in the context of ACL surgery [3] that patients with positive psychological responses before surgery and at the start of recovery were associated with a better return to sport, suggesting that attention to recovery psychological in addition to physical recovery could be justified.

Clinical screening for inappropriate psychological responses in athletes can help clinicians identify athletes at risk of not returning to their sport level.

The use of a questionnaire with numeric answers makes it possible to simplify the responses, and to quantify the patients' evolution. Such a questionnaire can be easily used by doctors and surgeons in their daily practice. Indeed, giving a patient permission to return to sport is a difficult decision to make, and there is no consensus on this subject [1]. The purpose of the score is to enable physicians to recognize patients who have psychological factors that prevent them from resuming their activities. Therefore, the practitioners will be able to offer them specific advice to overcome their apprehension.

In this study, the ceiling effect was $19.1 \%$, it has been varied between 6.7 and $33.8 \%$. By recalculating it on the retest values, the value of the ceiling effect is $16 \%$, ranging from 5.7 to $25 \%$; which corresponds to the value found in other studies $[5,13,17,28]$. These values of the ceiling 
effect can be explained by the fact that the patients have a median duration of 3 years postoperative, and by the good results of ankle ligament reconstruction [18, 22, 25].

All the patients were operated using the anatomic arthroscopic reconstruction technique. As mentioned previously many different chronic lateral instability surgical techniques exist, and their outcome seems to appear to be similar. This score should be able to be applied to all CLAI surgeries regardless of the method used.

A limitation present in this study was that the model for the ALR-RSI score was not originally developed for ankle instability. Indeed, the score was based on an adaptation of the ACL-RSI score, a validated score to quantify the psychological readiness of athletes to return to sport following surgical ACL reconstruction. Nevertheless, the questions are not specific to a certain articulation of the body, and can easily be transposed to other articulations implicated in sport injuries.

\section{Conclusion}

The ALR-RSI is a valid, reproducible scale to evaluate the relevant psychological factors in the return to the same sport after ankle ligament reconstruction.

\begin{abstract}
Author contribution FS, PAB, EK, PA and AM have made substantial contributions to acquisition of data, or analysis and interpretation of data. FS, AH, RL, PA and AS have been involved in drafting the manuscript or revising it critically. AH and FS have made substantial contributions to conception and design, or acquisition of data, or analysis and interpretation of data. Every author has given final approval of the version to be published and agrees to be accountable for all aspects of the work in ensuring that questions related to the accuracy or integrity of any part of the work are appropriately investigated and resolved.
\end{abstract}

Funding No funding was required for this study.

\section{Compliance with ethical standards}

Conflict of interest Some of the authors disclosed potential conflict of interest.

Ethical approval This study was approved by an Institutional Review Board (CPP IDF III, Hôpital Tarnier-Cochin) (Ref. CPP: 3730-NI; Ref CNRIPH: 19.06.17.35910). Informed consent was obtained from each patient

Informed consent Informed consent was obtained from each patient.

Open Access This article is licensed under a Creative Commons Attribution 4.0 International License, which permits use, sharing, adaptation, distribution and reproduction in any medium or format, as long as you give appropriate credit to the original author(s) and the source, provide a link to the Creative Commons licence, and indicate if changes were made. The images or other third party material in this article are included in the article's Creative Commons licence, unless indicated otherwise in a credit line to the material. If material is not included in the article's Creative Commons licence and your intended use is not permitted by statutory regulation or exceeds the permitted use, you will need to obtain permission directly from the copyright holder. To view a copy of this licence, visit http://creativecommons.org/licenses/by/4.0/.

\section{References}

1. Ardern CL, Bizzini M, Bahr R (2016) It is time for consensus on return to play after injury: five key questions. Br J Sports Med 50:506-508

2. Ardern CL, Taylor NF, Feller JA, Webster KE (2013) A systematic review of the psychological factors associated with returning to sport following injury. Br J Sports Med 47:1120-1126

3. Ardern CL, Taylor NF, Feller JA, Whitehead TS, Webster KE (2013) Psychological responses matter in returning to preinjury level of sport after anterior cruciate ligament reconstruction surgery. Am J Sports Med 41:1549-1558

4. Beaton DE, Bombardier C, Guillemin F, Ferraz MB (2000) Guidelines for the process of cross-cultural adaptation of self-report measures. Spine 25:3186-3191

5. Bohu Y, Klouche S, Lefevre N, Webster K, Herman S (2015) Translation, cross-cultural adaptation and validation of the French version of the anterior cruciate ligament-return to sport after injury (ACL-RSI) scale. Knee Surg Sports Traumatol Arthrosc 23:1192-1196

6. Clanton TO, Viens NA, Campbell KJ, Laprade RF, Wijdicks CA (2014) Anterior talofibular ligament ruptures, part 2: biomechanical comparison of anterior talofibular ligament reconstruction using semitendinosus allografts with the intact ligament. Am J Sports Med 42:412-416

7. Clement D, Arvinen-Barrow M, Fetty T (2015) Psychosocial responses during different phases of sport-injury rehabilitation: a qualitative study. J Athl Train 50:95-104

8. Garrick JG (1977) The frequency of injury, mechanism of injury, and epidemiology of ankle sprains. Am J Sports Med 5:241-242

9. Gerometta A, Klouche S, Herman S, Lefevre N, Bohu Y (2018) The shoulder instability-return to sport after injury (SIRSI): a valid and reproducible scale to quantify psychological readiness to return to sport after traumatic shoulder instability. Knee Surg Sports Traumatol Arthrosc 26:203-211

10. Guillo S, Bauer T, Lee JW, Takao M, Kong SW, Stone JW, Mangone PG, Molloy A, Perera A, Pearce CJ, Michels F, Tourné Y, Ghorbani A, Calder J (2013) Consensus in chronic ankle instability: aetiology, assessment, surgical indications and place for arthroscopy. Orthop Traumatol Surg Res 99:S411-419

11. Guillo S, Cordier G, Sonnery-Cottet B, Bauer T (2014) Anatomical reconstruction of the anterior talofibular and calcaneofibular ligaments with an all-arthroscopic surgical technique. Orthop Traumatol Surg Res 100:S413-417

12. Guillo S, Takao M, Calder J, Karlson J, Michels F, Bauer T, Ankle Instability Group (2016) Arthroscopic anatomical reconstruction of the lateral ankle ligaments. Knee Surg Sports Traumatol Arthrosc 24:998-1002

13. Ha JK, Kim JG, Yoon KH, Wang JH, Seon JK, Bae JH, Jang KM (2019) Korean version of the anterior cruciate ligament-return to sport after injury scale: translation and cross-cultural adaptation. Clin Orthop Surg 11:164-169

14. Hølmer P, Søndergaard L, Konradsen L, Nielsen PT, Jørgensen LN (1994) Epidemiology of sprains in the lateral ankle and foot. Foot Ankle Int 15:72-74 
15. Kitaoka HB, Alexander IJ, Adelaar RS, Nunley JA, Myerson MS, Sanders M (1994) Clinical rating systems for the ankle-hindfoot, midfoot, hallux, and lesser toes. Foot Ankle Int 15:349-353

16. Konradsen L, Bech L, Ehrenbjerg M, Nickelsen T (2002) Seven years follow-up after ankle inversion trauma. Scand J Med Sci Sports 12:129-135

17. Kvist J, Österberg A, Gauffin H, Tagesson S, Webster K, Ardern C (2013) Translation and measurement properties of the Swedish version of ACL-return to sports after injury questionnaire. Scand J Med Sci Sports 23:568-575

18. Lopes R, Andrieu M, Cordier G, Molinier F, Benoist J, Colin $\mathrm{F}$, Thès A, Elkaïm M, Boniface $\mathrm{O}$, Guillo $\mathrm{S}$, Bauer T, French Arthroscopic Society (2018) Arthroscopic treatment of chronic ankle instability: prospective study of outcomes in 286 patients. Orthop Traumatol Surg Res 104:S199-S205

19. Lopes R, Decante C, Geffroy L, Brulefert K, Noailles T (2016) Arthroscopic anatomical reconstruction of the lateral ankle ligaments: a technical simplification. Orthop Traumatol Surg Res 102:S317-S322

20. Lui TH (2007) Arthroscopic-assisted lateral ligamentous reconstruction in combined ankle and subtalar instability. Arthroscopy 23:554.e1-5

21. Mabit C, Tourné Y, Besse J-L, Bonnel F, Toullec E, Giraud F, Proust J, Khiami F, Chaussard C, Genty C, Sofcot (French Society of Orthopedic, and Traumatologic Surgery) (2010) Chronic lateral ankle instability surgical repairs: the long term prospective. Orthop Traumatol Surg Res 96:417-423

22. Maffulli N, Del Buono A, Maffulli GD, Oliva F, Testa V, Capasso G, Denaro V (2013) Isolated anterior talofibular ligament Broström repair for chronic lateral ankle instability: 9-year follow-up. Am J Sports Med 41:858-864

23. Michels F, Cordier G, Guillo S, Stockmans F, ESKKA-AFAS Ankle Instability Group (2016) Endoscopic ankle lateral ligament graft anatomic reconstruction. Foot Ankle Clin 21:665-680
24. Mokkink LB, Terwee CB, Patrick DL, Alonso J, Stratford PW, Knol DL, Bouter LM, de Vet HCW (2010) The COSMIN study reached international consensus on taxonomy, terminology, and definitions of measurement properties for health-related patientreported outcomes. J Clin Epidemiol 63:737-745

25. Nery C, Raduan F, Del Buono A, Asaumi ID, Cohen M, Maffulli N (2011) Arthroscopic-assisted Broström-Gould for chronic ankle instability: a long-term follow-up. Am J Sports Med 39:2381-2388

26. Podlog L, Heil J, Schulte S (2014) Psychosocial factors in sports injury rehabilitation and return to play. Phys Med Rehabil Clin N Am 25:915-930

27. Roos EM, Brandsson S, Karlsson J (2001) Validation of the foot and ankle outcome score for ankle ligament reconstruction. Foot Ankle Int 22:788-794

28. Salatkaite S, Šiupšinskas L, Gudas R (2019) Translation and cultural adaptation of Lithuanian version of the anterior cruciate ligament return to sport after injury (ACL-RSI) scale. PLoS ONE 14:e0219593

29. Shawen SB, Dworak T, Anderson RB (2016) Return to Play Following Ankle Sprain and Lateral Ligament Reconstruction. Clin Sports Med 35:697-709

30. Song Y-J, Hua Y-H (2019) Similar outcomes at early term after arthroscopic or open repair of chronic ankle instability: a systematic review and meta-analysis. J Foot Ankle Surg 58:312-319

31. Webster KE, Feller JA, Lambros C (2008) Development and preliminary validation of a scale to measure the psychological impact of returning to sport following anterior cruciate ligament reconstruction surgery. Phys Ther Sport Sports Med 9:9-15

Publisher's Note Springer Nature remains neutral with regard to jurisdictional claims in published maps and institutional affiliations. 